\title{
ANALISIS QoS (Quality of Service) JARINGAN UNBK DENGAN MENGGUNAKAN MICROTIC ROUTER (Studi Kasus : Jaringan UNBK SMAN 1 Jakenan Pati)
}

\author{
Ratih Nindyasari ${ }^{1)}$, Alif Catur Murti ${ }^{2)}$, Muhammad Imam Ghozali ${ }^{3)}$ \\ 1)23) Program Studi Teknik Informatika, Fakultas Teknik, Universitas Muria Kudus \\ Jl. Lingkar Utara, Gondangmanis, Bae, Kudus \\ Email : ratih.nindyasari@umk.ac.id ${ }^{l)}$
}

\begin{abstract}
Abstrak
Kebutuhan akan ketersediannya layanan jaringan yang cepat, kestabilan jaringan, dan kesesuaian dengan teknologi yang digunakan menjadi kebutuhan primer bagi masyarakat. Penggunaan teknologi pada zaman sekarang sudah menyentuh semua aspek kehidupan. Aspek pendidikan merupakan salah satu yang terkena dampak dari perkembangan teknologi, khususnya internet. Bentuk nyata dari dampak yang muncul adalah Prosedur Operasional Standar (POS) yang dikeluarkan Badan Standar Nasional Pendidikan (BNSP) di tahun 2017 untuk diadakannya Ujian Nasional Berbasis Komputer (UNBK). Kondisi tersebut membuat beberapa sekolah yang menjadi percontohan mempersiapkan diri dengan mulai membangun ruang ujian yang didesain dengan perangkat komputer dan jaringan internet. Penambahan router pada node awal dan menggunakan manajemen switch mengakibatkan adanya perbedaan dalam pengujian QoS. Dengan adanya penambahan router pada topologi jaringan UNBK ini menjadikan tidak adanya packet loss ketika dilakukan pengujian seperti pada desain topologi jaringan tanpa menggunakan router. Penggunaan server lokal dalam setiap lab memungkinan untuk membackup server yang ada di lab lain ketika terjadi kondisi server down. Sehingga desain topologi jaringan dengan menggunakan router ini dapat diimplementasikan dalam jaringan UNBK pada SMAN 1 Jakenan Pati.
\end{abstract}

Kata kunci : Topologi Jaringan, Quality of Service, UNBK, Router Mikrotik, Packet Loss.

\begin{abstract}
The requirement of network service availability, stability, and conformity with technology used is a primary need for community. Today, the use of technology has touched all aspects of life. The educational aspect is one that affected by technological developments, especially internet. The real form of impact that arises is Standard Operational Procedure (POS) issued by Badan Standar Nasional Pendidikan (BNSP) in 2017 for holding project Ujian Nasional Berbasis Komputer (UNBK). This condition made several schools that became the pilot prepare themselves by starting to build test rooms designed with computer devices and internet networks. Adding a router to initial node and using switch management results in differences in QoS testing. With the addition of routers in the UNBK network topology, there is no packet loss when testing not like the design of network topologies without using a router. The use of local servers in each lab makes it possible to back up a server in other lab when a server condition is down. The network topology design using this router can be implemented in the UNBK network at SMAN 1 Jakenan Pati.
\end{abstract}

Keywords : Network Topology, Quality of Services, UNBK, Microtic Router, Packet Loss.

\section{PENDAHULUAN}

Kualitas pelayanan pada suatu kegiatan jasa menjadi suatu hal yang penting, dikarenakan dapat mempengaruhi produktivitas pelaku yang menggunakan pelayanan tersebut, khususnya pengguna teknologi. Kecepatan dalam mengakses internet pada saat ini menjadi fokus dari penyedia jasa layanan internet atau provider. Kecepatan internet tidak hanya dipengaruhi oleh provider itu sendiri, tetapi juga dalam hal mendesain suatu topologi jaringan komputer. Topologi jaringan internet harus disesuaikan dari kebutuhan lapangan, contoh bentuk gedung dan ketersediaan sumberdaya (resource). Topologi jaringan yang tepat akan meningkatkan efektifitas, efisiensi dan juga produktivitas dari pengguna (user). Pemerintah khususnya bidang pendidikan di tahun 2017 mengadakan adanya Ujian Nasional Berbasis Komputer (UNBK), untuk beberapa sekolah sebagai percontohan. Pelaksanaan UNBK tertuang pada aturan yang dikeluarkan Badan Standar Nasional Pendidikan (BSNP) nomor 0044/P/BSNP/XI/2017. Menindaklanjuti 
hal tersebut munculnya Standar Operasional Prosedur (SOP) membuat sekolah percontohan harus menyediakan kualitas layanan yang optimal dan minim gangguan. Tim teknis UNBK selaku koordinator berkomunikasi dengan tim teknisi untuk mendesain kebutuhan jaringan komputer yang ada, dengan tujuan meningkatkan kualitas [1].

Pengukuran kualitas suatu jaringan komputer dilakukan dengan standar Quality of Service (QoS). $Q o S$ didesain untuk membantu pengguna (user) agar menjadi lebih produktif dengan cara memastikan bahwa pengguna mendapatkan kualitas yang optimal dari sebuah jaringan komputer. QoS juga menyediakan kualitas dari jaringan komputer walaupun dengan penggunaan teknologi yang berbeda. Kualitas dari sebuah jaringan komputer dipengaruhi oleh bandwidth, jarak, dan traffic dalam topologi jaringan [2]. Penelitian tentang penggunaan $Q o S$ untuk mengukur kualitas jaringan internet pernah dilakukan di UPT Loka Uji Teknik Pengembangan Jambang Kulon-LIPI. Pada penelitian tersebut $Q o S$ digunakan untuk mengukur kualitas jaringan internet. Pada penelitian ini penulis menggunakan aplikasi wireshark sebagai perkakas bantu untuk pengukuran QoS. Wireshark merupakan perkakas bantu yang digunakan untuk menemukan masalah yang ada pada jaringan. QoS disebut memiliki fitur untuk memprediksi kebutuhan dari bandwidth yang disesuaikan dengan jarak [2]. Penelitian terkait desain topologi jaringan pernah dilakukan untuk perancangan dan pengembangan jaringan VLAN pada Dili Institute of Technologi (DIT) Timor Leste. Pada penelitian ini memfokuskan tentang bagaimana meningkatkan performansi jaringan dari beberapa divisi yang saling terpisah dengan membandingkan dua buah model jaringan. Uji coba penelitian ini menggunakan perkakas bantu berupa aplikasi packet tracer, dimana aplikasi ini memungkinkan untuk merancang sebuah jaringan besar secara virtual dengan detail pengalamatan (addressing) komputer. Hasil dari penelitian ini menunjukkan konfigurasi VLAN dengan menggunakan metode trunking switch yang dihubungkan dengan router dapat meningkatkan performansi jaringan [3]. Berdasarkan berbagai literatur yang menyatakan bahwa $Q o S$ dapat diterapkan dan digunakan untuk permasalahan terkait penyediaan kualitas layanan jaringan, maka dalam penelitian ini digunakan $Q o S$ untuk menganalisis kualitas topologi jaringan UNBK. Hasil dari pengukuran kualitas jaringan dapat digunakan sebagai acuan atau rekomendasi dalam membangun jaringan UNBK di sekolah.

\section{DASAR TEORI}

\subsection{Penelitian Terkait}

Beberapa penelitian yang telah mengkaji tentang desain topologi jaringan sudah pernah dilakukan oleh [4]. Penelitian ini menguji komunikasi data untuk masing-masing topologi dan hubungan antar topologi. Tujuan utama dari penelitian ini adalah untuk mengetahui topologi yang memiliki kecepatan komunikasi data yang tinggi dan hemat dalam biaya konstruksi. Topologi yang diteliti adalah jenis topologi point to point, Multipoint, BUS, Ring, Star, Tree, Mesh, dan Hybrid [4]. Penelitian berikutnya yang dilakukan Parasian Silitonga dan Irene Sri Morina dengan judul “Analisis QoS (Quality of Service) Jaringan Kampus dengan Menggunakan Microtic Routerboard". Penelitian ini menjawab tentang tuntutan perkembangan dan penggunaan teknologi komputer di Universitas Katolik Santo Thomas S.U. Analisa $Q o S$ digunakan dalam manajemen bandwidth yang dilakukan dengan menggunakan Microtic RouterOS yang berbasis Linux. Hasilnya menunjukkan penggunaan bandwidth lebih baik dan merata, serta pengelolaan IP Address dan topologi jaringan kampus memberikan dampak penggunaan jaringan yang lebih baik dan menghilangkan IP conflict di setiap unit [5]. Perbedaan penelitian ini dengan penelitian sebelumnya terletak pada konsep perancangan topologi jaringan yang dibangun dan disesuaikan dengan keutuhan dari UNBK yang kemudian diukur kualitasnya dengan menggunakan standar $Q o S$. Penerapan $Q o S$ ini juga sudah pernah dilakukan dengan menggunakan metode Hierarchical Token Bucket (HTB) [6] dikatakan dapat memaksimalkan bandwidth yang dipakai.

\subsection{Quality of Service (QoS)}

Quality of Service $(Q o S)$ merupakan teknologi yang diterapkan dalam jaringan komputer untuk memberikan layanan yang optimal dan adil bagi para pengguna jaringan komputer. $Q o S$ memungkinkan administrator jaringan untuk dapat menangani berbagai efek akibat terjadinya kemacetan (congestion) pada lalu lintas aliran paket di dalam jaringan [5]. Analisis Quality of Service $(Q o S)$ digunakan untuk mengetahui kualitas dari topologi jaringan internet yang dibangun, sehingga tujuan akhir yaitu produktivitas, dan efisiensi jaringan dapat meningkat [2]. 


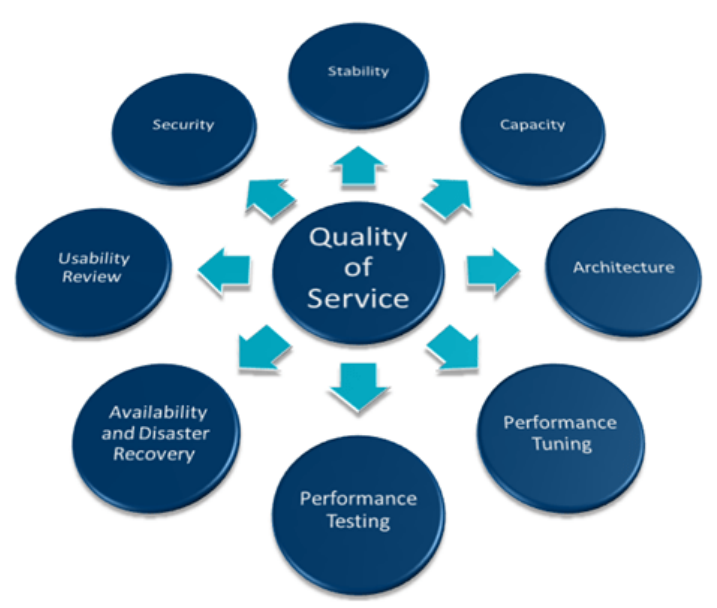

Gambar 1. Bagan Quality of Service

\subsection{Topologi Jaringan}

Topologi jaringan merupakan bagaimana sebuah komputer dan perangkat teknologi lainnya saling terhubung. Konsep dasar topologi jaringan adalah point to point, kemudian berkembang menjadi multi point dimana nama topologi didasarkan pada bentuk jaringan yang terhubung. Topologi jaringan disesuaikan dengan kebutuhan dan sumberdaya yang digunakan, beberapa jenis topologi adalah bus, ring, star, extended star, tree/hierarchical, dan mesh seperti yang terlihat pada gambar 2 [4].

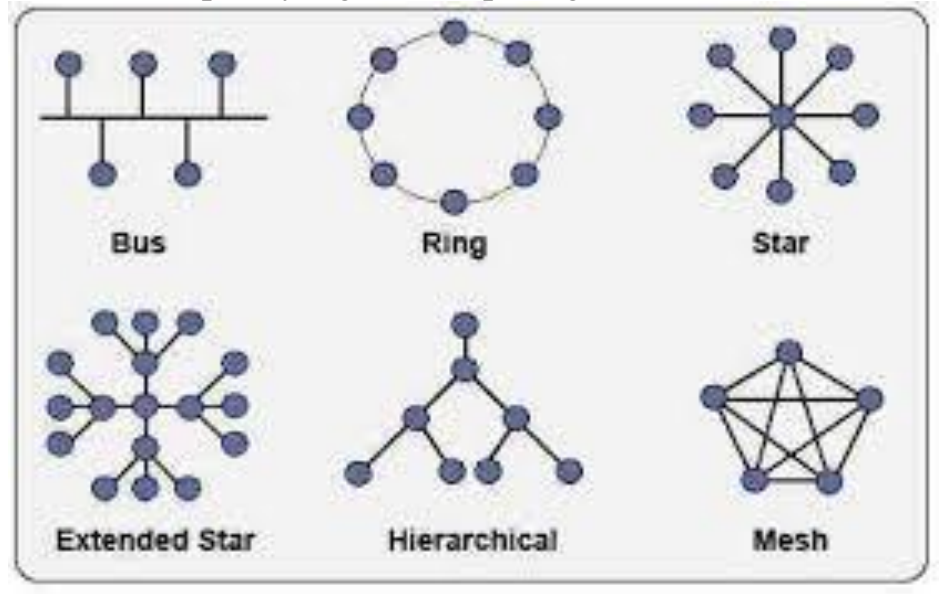

Gambar 2. Jenis Topologi Jaringan

\section{METODOLOGI PENELITIAN}

Dalam penelitian ini diperlukan beberapa tahapan untuk mendukung berlangsungnya penelitian sesuai yang direncanakan. Gambar Alur Metodologi Penelitian dapat dilihat pada Gambar 3. Berikut merupakan alur penelitian yang akan dilakukan :

Identifikasi Masalah

Pada tahapan ini dilakukan identifikasi masalah yang ada, yakni melakukan kajian yang menyeluruh tentang yang terjadi di lapangan yakni tepatnya di SMA/SMK yang menjadi tempat lokasi UNBK dan mengetahui bagaimana alur / cara kerja pelaksanaan UNBK di sekolah.

Pengumpulan Data

Pada tahap ini kegiatan yang dilakukan adalah mengumpulkan data tentang : a). Data dari observasi langsung di lapangan (SMA 1 Jakenan Pati), b). Testing dan Implementasi menggunakan perkakas bantu Packet Tracer, c). melakukan kajian dari beberapa literatur tentang topologi jaringan dan Quality Of Service (QoS). 
Analisis dan Perancangan

Sebelum membuat topologi jaringan tentu akan dilakukan analisa kebutuhan dari sisi sumber daya komputer dan kondisi gedung serta biaya yang nantinya akan dikeluarkan. Setelah itu dilakukan proses perancangan secara virtual dengan menggunakan bantuan perkakas bantu Packet Tracer.

Uji Coba

Pada tahapan ini akan dilakukan uji coba berdasarkan pada topologi yang dibuat. Pengujian dilakukan terhadap beberapa parameter yaitu kecepatan pengiriman paket, kecepatan transfer data, dan adanya paket loss.

Analisis Quality of Service (QoS)

Data-data informasi yang sudah didapatkan pada tahap analisis dengan menggunakan standar Quality of Service $(Q o S)$. Sehingga kedepannya dengan konsep jaringan topologi yang dibangun kegiatan berjalan dengan lancar.

Pembuatan Laporan

Pada tahap ini semua hasil dan data penelitian akan dirangkum dan disajikan dalam tabel sehingga mudah dipahami oleh pembaca.

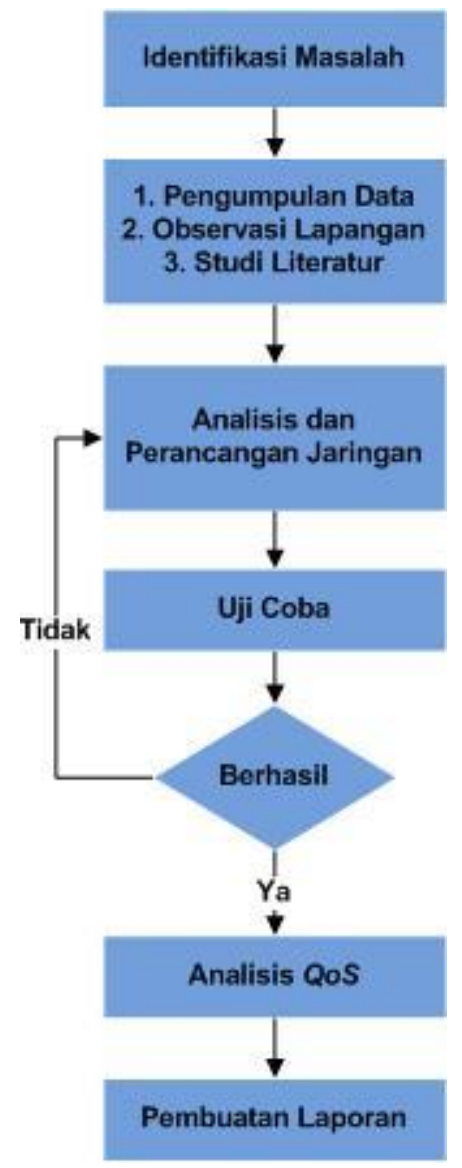

Gambar 3. Alur Penelitian

\section{HASIL DAN PEMBAHASAN}

4.1. Hasil Monitoring Pada Topologi Jaringan

Berdasarkan pada hasil identifikasi permasalahan yang terjadi di dalam jaringan UNBK di SMAN 1 Jakenan Pati, menunjukkan permasalahan utama yaitu banyaknya packet loss ketika pengiriman data. Packet loss ini dapat terjadi juga akibat besar kecilnya bandwidth. Semakin besar bandwidth maka jumlah 


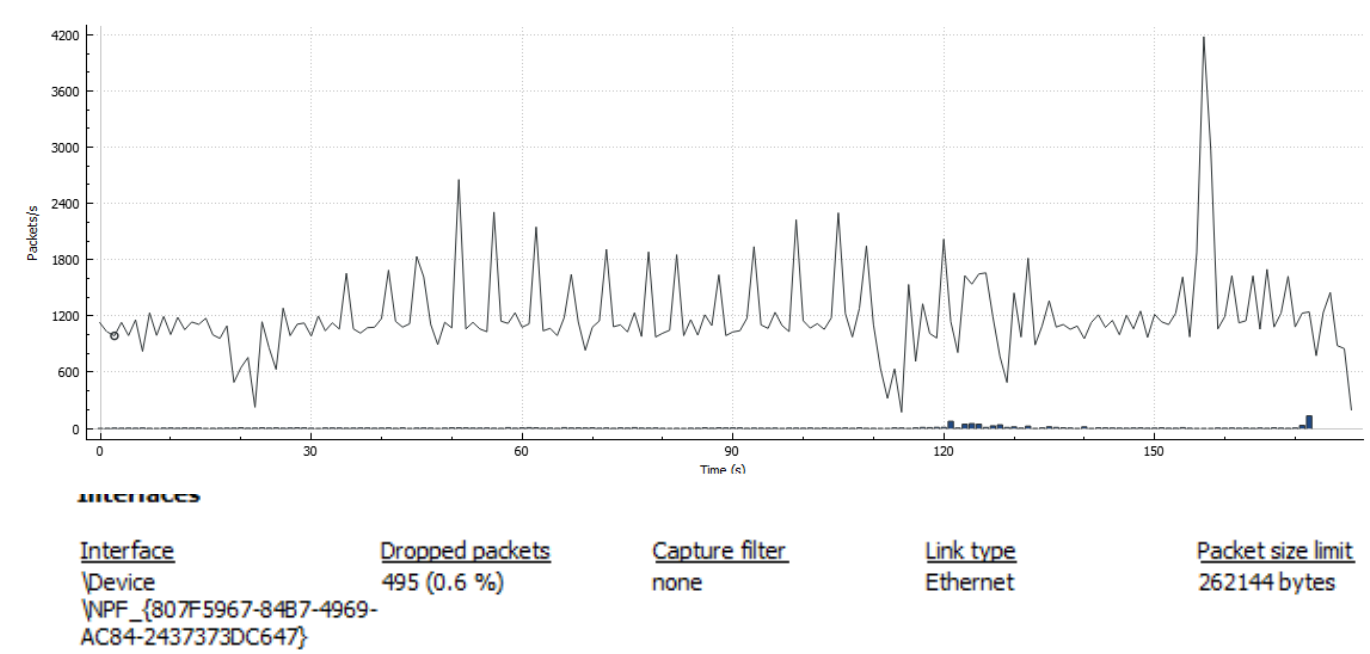

Gambar 6. Grafik Banyaknya Packet Loss

\subsection{Hasil Monitoring Topologi Jaringan Menggunakan Router Microtic}

Setelah dilakukan pengamatan pada topologi jaringan yang terdapat pada Gambar 4, maka saat ini dilakukan perancangan kembali topologi jaringan yang baru. Desain topologi jaringan yang baru ini dibuat dengan menambahkan router microtic. Berikut ini adalah hasil desain topologi jaringan dengan menggunakan router microtic pada SMAN 1 Jakenan Pati yang dapat dilihat pada Gambar 7.

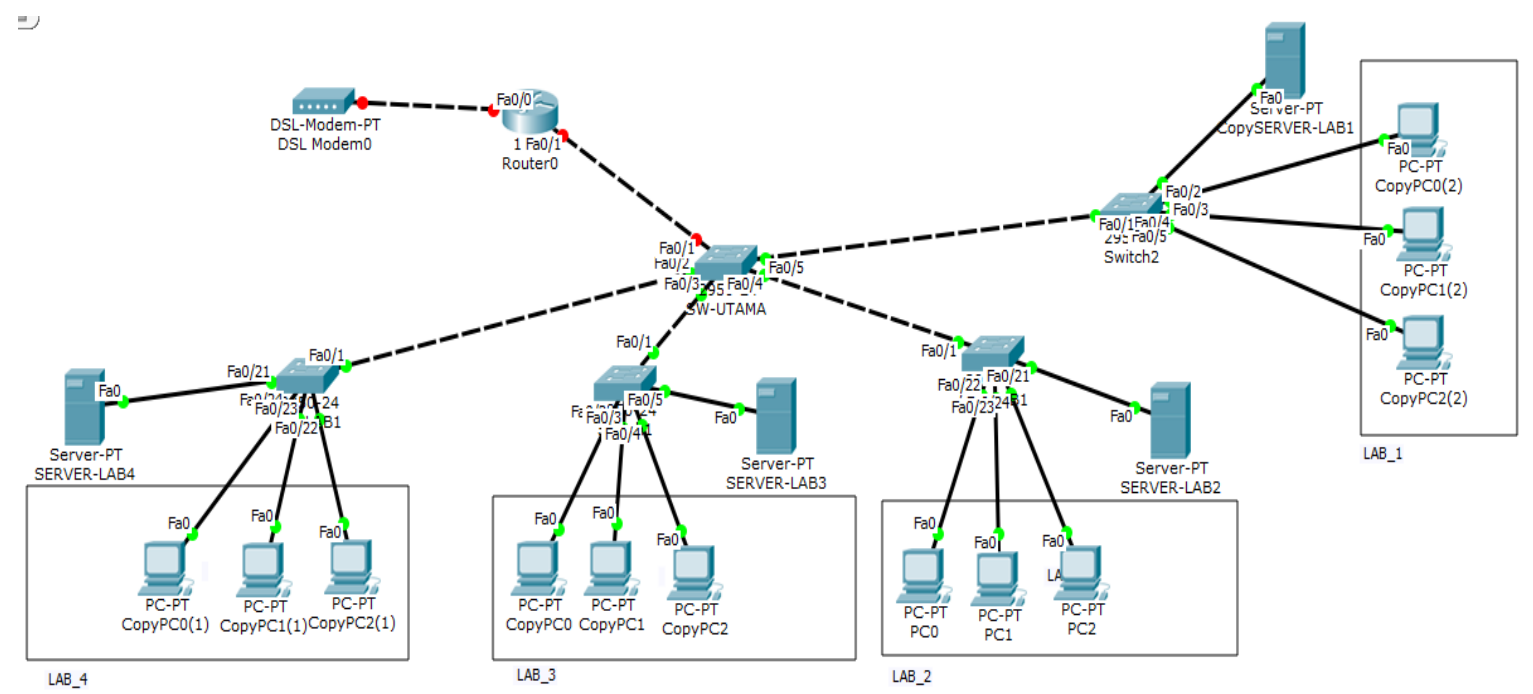

Gambar 7. Topologi Jaringan dengan Router Microtic

Skema topologi jaringan usulan ini dilakukan dengan menambahkan sebuah router di depan modem sebelum menuju switch utama dan ke switch pada masing - masing lab. 


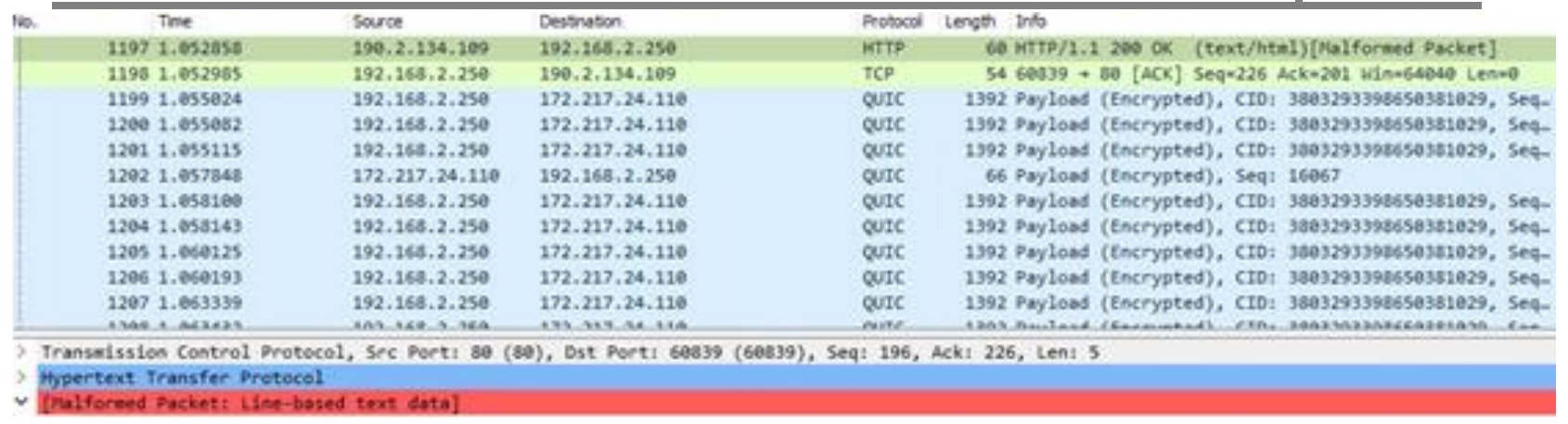

Gambar 8. Monitoring TCP pada Topologi Jaringan dengan Router Mikrotik

Pada Gambar 8 merupakan hasil pengamatan yang dilakukan dengan aplikasi wireshark pada jaringan yang telah ditambahkan router mikrotik. Terlihat dari beberapa alamat IP pada bagian Source ke alamat IP pada bagian Destination terlihat adanya protocol yang dilalui dan panjangnya paket saat dilakukan pengiriman data.

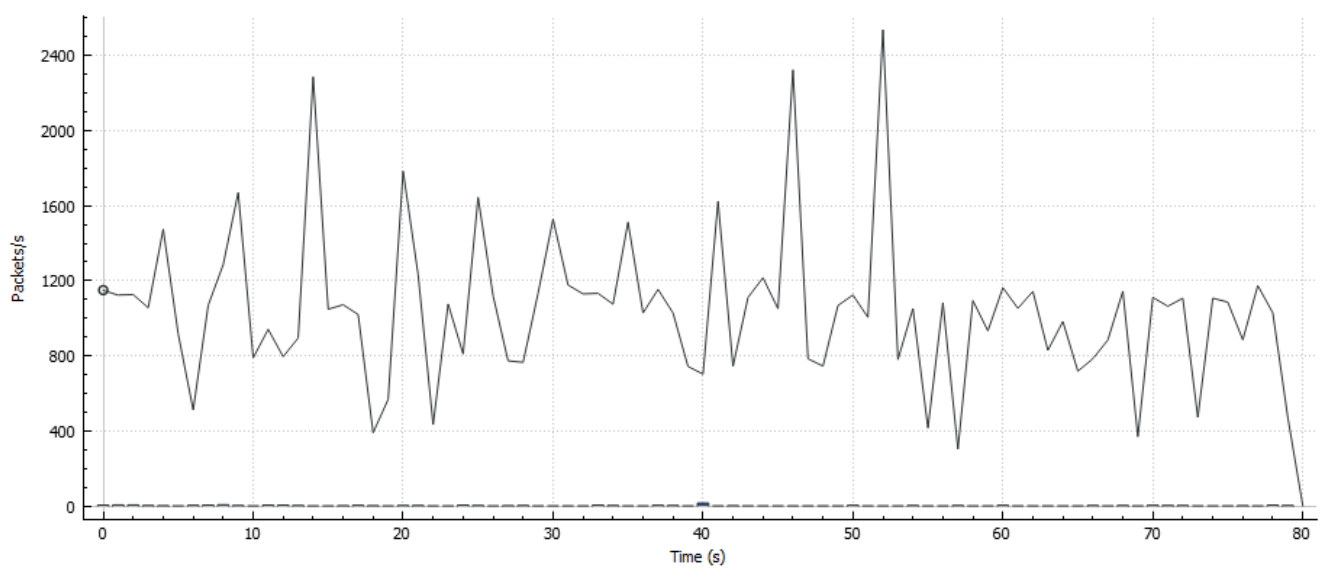

Interfaces

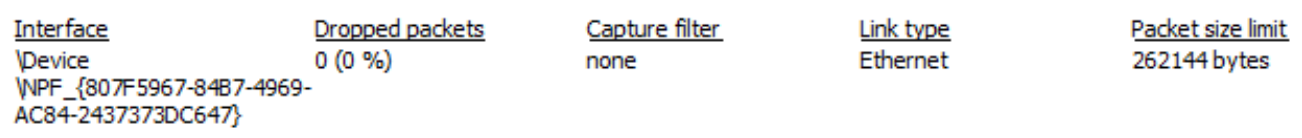

Gambar 9. Grafik Packet Loss Pada Jaringan dengan Router Microtic

Berdasarkan pada Gambar 8. terlihat bahwa tidak ada packet loss dengan hasil 0. Pengamatan ini dilakukan sama seperti pada skenario 1 dan skenario 2 yang telah dilakukan pada topologi jaringan sebelumnya.

\section{KESIMPULAN}

Berdasarkan pada hasil dan pembahasan pada bagian sebelumnya maka pada bagian ini dapat diambil kesimpulan bahwa dalam jaringan yang sebelumnya yaitu tanpa menggunakan router, ketika dilakukan analisis QoS menunjukkan hasil adanya packet loss dan TCP error pada saat dilakukan skenario 1 dan 2. Kemudian setelah dilakukan penambahan router pada titik awal dan menggunakan manajemen switch mengakibatkan adanya perbedaan hasil pengujian $Q o S$. Pada pengamatan Topologi Jaringan dengan menggunakan router menunjukkan tidak adanya packet loss. Berdasarkan pada hasil pengujian pada Topologi Jaringan setelah dilakukan penambahan router maka bentuk desain topologi jaringan yang telah dilakukan pengujian dengan menggunakan skenario 1 dan 2 ini dapat ditarik kesimpulan bahwa Topologi 
Jaringan yang dibangun dengan menggunakan microtic router lebih layak dan dapat digunakan oleh SMAN 1 Jakenan Pati dalam membantu meningkatkan performansi jaringan UNBK.

\section{DAFTAR PUSTAKA}

[1] BSNP, Prosedur Operasional Standar Penyelenggaraan Ujian Nasional Tahun Pelajaran 2017/2018, NOMOR: 0044/P/BSNP/XI/2017.

[2] R. Wulandari, “ANALISIS QoS (QUALITY OF SERVICE) PADA JARINGAN INTERNET (STUDI KASUS : UPT LOKA UJI TEKNIK PENAMBANGAN JAMPANG KULON - LIPI ),” J. Tek. Inform. dan Sist. Inf., vol. 2, pp. 162-172, 2016.

[3] Guterres, L, E, J., Triyono, J., Nurnawati, E, K.,, "Perancangan Dan Pengembangan Jaringan Vlan Pada Dili Institute Of Technology (Dit) Timor Leste Menggunakan Packet Tracer", J.JARKOM, vol .1, no. 2, pp. 131-141, 2014.

[4] A. Anjum and S. A. Pasha, "- A Brief View of Computer Network Topology for Data Communication and Networking \|," Int. J. Eng. Trends Technol., vol. 22, no. 7, pp. 319-324, 2015.

[5] Silitonga, P., Morina, I, S.,2014 "Analisis QoS (Quality of Service) Jaringan Kampus dengan Menggunakan Microtic Routerboard", Jurnal TIMES, Vol III No 2 : 19-24

[6] A. W. Azinar and R. S. Adi, "ANALISIS QOS (QUALITY OF SERVICE) PADA WARNET DENGAN METODE HTB (HIERARCHICAL TOKEN BUCKET)," J. Ilm. NERO, vol. 3, no. 1, pp. 45-52, 2017. 